\title{
Changing Lifestyle Improves Executive Functions and Associated Neurophysiological Activity in Children with Autism
}

\author{
Agnes S. Chan ${ }^{1-3^{*}}$ and Sophia L. Sze ${ }^{1,2}$
}

*Correspondence: aschan@cuhk.edu.hk

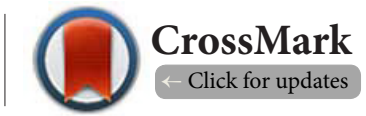

${ }^{1}$ Neuropsychology Laboratory, Department of Psychology, The Chinese University of Hong Kong, Shatin, Hong Kong SAR, China. ${ }^{2}$ Chanwuyi Research Center for Neuropsychological Well-Being, The Chinese University of Hong Kong, Shatin, Hong Kong SAR, China. ${ }^{3}$ Henan Songshan Research Institute for Chanwuyi, Henan 452470, China.

\begin{abstract}
Background: People with autism spectrum disorders (ASD) are commonly found to have executive dysfunctions that are associated with aberrant activity in the prefrontal cortex (PFC) and anterior cingulate cortex (ACC). Previous empirical studies found that changing the lifestyle of a group of children with ASD according to a Chinese Chan-based medical principle for one month enhanced their executive functions and related neural activity patterns. The present study aimed to explore the effects of this lifestyle change at a longer term (i.e., six months).

Methods: Thirty children with ASD participated in this study with half in the experimental (sixmonth lifestyle change) and the other half in the control (no change) group. Each child was assessed on his/her executive functions, behavioral problems based on parental ratings, and event-related electroencephalographic (EEG) activity during an executive control task before and after six months.

Results: A pre-post comparison demonstrated significantly improved inhibitory control, mental flexibility, and planning abilities in the experimental group, which coincided with improved parental ratings of their daily behavior problems. Yet, the control group did not show such improvements. The sLORETA analysis results also revealed significantly increased activity across the PFC and ACC regions, particularly in the right hemisphere, during an inhibitory control task in the experimental group, while the control group did not show any significant alteration in the neural system.
\end{abstract}

Conclusions: The findings supported a positive effect of the Chan-based lifestyle changes in children with ASD for improving their executive function.

Keywords: Autism, executive function, lifestyle intervention, prefrontal cortex, anterior cingulate cortex, electroencephalogram

\section{Introduction}

Executive dysfunction refers to difficulties in response inhibition, mental flexibility, self-monitoring, planning, and/or working memory. Such cognitive deficits are common in people with autism spectrum disorders (ASD) [1-2]. The executive dysfunction is suggested to be accounted for the typical clinical manifestation of ASD, including uncontrollable behavioral and emotional reactions, repetitive behavior, strong need for sameness, restricted interests, and inappropriate social communication and interaction. Given that executive functioning is an umbrella term covering a wide range of cognitive abilities, its deficiency has pervasive effects on everyday functioning, independent living, and caregiving in individuals with ASD.

Majority of the common interventions designed to enhance specific executive functions (e.g., self-control) have been primarily behavioral based [3-7], some interests have been developed to explore potential alternative interventions for improving executive function and reducing the behavioral problems of individuals with ASD. The alternative interventions that have been studied include massage [8], acupuncture [9], music therapy [10], and dietary/nutritional interventions [11-12].

Some studies have suggested that therapeutic lifestyle

(C) 2020 Chan; licensee Herbert Publications Ltd. This is an Open Access article distributed under the terms of Creative Commons Attribution License 
changes could have positive effects on cognitive functions, behavior, and physical and mental health [13-16]. While the majority of these studies have been conducted on elderly [17-21], a few studies have been conducted on younger populations [13,22-24]. Our research team has conducted a series of studies on the effects of a traditional Chinese Chan-based lifestyle intervention, namely Dejian Mind-Body Intervention (DMBI), on enhancing executive functioning in ASD, and we have observed some encouraging results [25-30]. The Chinese Chan-based lifestyle intervention is based on a branch of traditional Chinese medicine called Chanyi, which has a thousand years of history and clinical application [31-32]. As a lifestyle intervention, it is assumed that individuals have the ability to change their patterns of thought and behavior to enhance their mental and physical health through improving their way of life. While most Western lifestyle interventions emphasize the adoption of healthy diet and exercise, cognitively stimulating activities, and good social relationships [13-24], the Chinese Chan-based lifestyle intervention is a holistic approach that comprises unique components to enhance both physical and psychological health including self-realization and personal growth, mind-body exercise (i.e., Nei Gong) practice, diet modification, and clearance of bodily orifices (i.e., openings). Recent empirical studies on the Chan-based lifestyle intervention have revealed positive improvements in physical health, mood, and cognitive functions in community-dwelling adults [33-34], elderly people with memory problems [35-38], children with autism/Asperger's disorder [25-30], and individuals with brain damage [39] and depression [40-42].

In specific, the effects of this Chan-based lifestyle intervention on ASD were studied with two randomized controlled trials. One study investigated the effect of the Chan-based diet modification [28] and the other study examined the effect of the mind-body exercise [25]. Individuals who applied either diet modification or mind-body exercise for one month demonstrated significant improvement on their behavioral and emotional problems. Their improved self-control ability coincided with significantly elevated event-related neuroelectrophysiological activity in the anterior cingulate cortex (ACC) that was suggested to play a crucial role in inhibitory control and self-monitoring [43-45]. None of these effects were found in the control group participants who did not change their diet or who had practiced conventional relaxation training. Although these two studies have provided empirical support for the short-term effects of the Chan-based lifestyle intervention, its therapeutic effects over a longer term remain largely unknown.

The potential long-term effects on children with ASD have been explored in two case studies. One study has reported significant reduction in temper tantrums, repetitive behaviors, problem-solving skills and psychosocial functioning of an adolescent with Asperger's disorder throughout a three-month Chan-based lifestyle intervention [29]. Another study found that the executive functions (including inhibitory control and cognitive flexibility) and memory ability of a low-functioning autistic child have improved from severely-to-moderately impaired range to borderline to average range after eightmonth lifestyle intervention. Such enhancement in cognitive functions synchronized with his increased EEG cordance (an index correlated with cerebral perfusion) across the cortex [27]. Given the encouraging findings of our previous case studies, the aim of this study was to examine the treatment outcomes of a six-month Chan-based lifestyle intervention on the executive functions with a control-design experiment. It was anticipated that children receiving the lifestyle intervention would demonstrate a significantly greater improvement in executive functions, as compared with the control group. In addition, it is anticipated that the treatment effect of a six-month intervention will be to a greater extent than that of a short-term one-month intervention in our previous studies $[25,28]$.

This study also explored the possible neural mechanisms underlying the potential long-term effects of the Chan-based lifestyle intervention by examining the pre-post alteration in the neuroelectrophysiological activity of ASD children while performing an executive control task. Extensive neuroimaging and electrophysiological studies have revealed that a distributed neural network involving the inferior frontal cortex (IFC; BA10/47), dorsolateral prefrontal cortex (DLPFC; BA9/46), pre-supplementary motor area (pSMA; BA6), and anterior cingulate cortex (ACC; BA24/32) plays a crucial role in mediating executive control of behavior involving response selection, inhibition, and monitoring [46-48]. Cumulative research findings suggest that children and adults with ASD have reduced functional activity in the IFC, DLPFC and ACC as compared with normal counterparts, which is associated with the executive control deficits in ASD [43-44,49-50]. Given the consistent empirical evidence for the positive effects of the Chan-based lifestyle intervention on executive control and related brain activity in children with ASD [25-30], the present study aimed to further investigate its effect on the neural activity patterns of the frontal brain regions and the ACC. It was anticipated that the six-month lifestyle intervention would enhance the neuroelectrophysiological activity of the ACC (which has been reported in previous one-month intervention studies) and an extensive area of the frontal lobe compared with those not receiving the intervention.

\section{Methods}

\section{Participants}

Forty-eight children with ASD aged between 7 and 17 years old were participated in the study. The children were recruited from the database of the Neuropsychology Laboratory of the Chinese University of Hong Kong and from two local schools in Hong Kong. All children had received formal clinical assessment at the Child Assessment Centres of the Department of Health or the general hospitals of the Hospital Authority in 
Hong Kong by a psychiatrist, a pediatrician or a clinical psychologist before they participated in our study. To double confirm their diagnosis, our clinical psychologist conducted a detailed clinical interview with each parent based on the diagnostic criteria of the Diagnostic and Statistical Manual of Mental Disorders, 5th edition (DSM-5) [51] and the Autism Diagnostic Interview-Revised (ADI-R) [52]. It is confirmed that all children have met the criteria of Autism Spectrum Disorders. The interview covers detailed questions about the early development and current functioning of the child, with higher scores indicating more severe autistic symptoms. The study was conducted in accordance with the Helsinki Declaration of the World Medical Association Assembly. The research protocol was approved by the Human Subjects Ethics Sub-committee of the Hong Kong Polytechnic University (Ref. No.: HSEARS20111215002) and the Chinese Clinical Trial Registry (Registration No.: ChiCTR-TRC-11001854). Written consent was obtained from the parent of each participant prior to the study.

Four children declined to participate before the first assessment and six children with other neurodevelopmental, psychiatric or neurological comorbidities, or who had been prescribed psychiatric medication were excluded from the study. Among the remaining 32 children, 15 children, whose parents could bring them to the intervention sessions and commit to attend all intervention sessions, received the six-month Chan-based lifestyle intervention. They served as the experimental group. The other 17 children served as the control group because they could not attend many of the intervention sessions due to children's or their parents' other activity engagement. At the six-month post assessment, two of the children from the control group dropped out of the study. Table 1 shows that the children in the two groups were matched on age, $t(28)=0.29, p=0.77$, gender, $x^{2}(1)=0.24$, $p=0.62$, and severity of autistic symptoms as measured by the three ADI-R subscales, with $t$ ranging from -1.43 to 0.74 , and $p$ ranging from 0.17 to 0.47 . The two groups also demonstrated comparable levels of general intelligence, $t(28)=-0.10, p=0.92$.

\section{Procedures}

Before the baseline assessment, all of the children and their parents were briefed on the procedure of the study and informed consent was obtained from the parents. A clinical psychologist assessed the children's developmental and medical history based on a structured clinical interview with the parents and the parents' ratings of their children's daily behavioral manifestation of executive dysfunction using five standardized questionnaires. Meanwhile, trained research assistants assessed the children's intellectual functioning, executive functions with neuropsychological assessment, and measured their electroencephalographic (EEG) activities individually. The clinical psychologist and research assistants who conducted the assessments were blinded to the rationale of the study and the group assignment. During the EEG recording, each child was required to perform a Go/No-Go task while their EEG data were obtained by a TruScan measuring

Table 1. Baseline Demographic and Clinical Characteristics of Participants in the Control and Experimental Groups.

\begin{tabular}{|c|c|c|c|c|}
\hline Characteristics & $\begin{array}{l}\text { Control Group } \\
\quad(n=15)\end{array}$ & $\begin{array}{l}\text { Experimental Group } \\
\qquad(n=15)\end{array}$ & $t / \chi^{2}$ & $P$ value \\
\hline Age $($ mean $\pm S D)$, years & $11.60 \pm 2.64$ & $11.88 \pm 2.70$ & 0.29 & 0.77 \\
\hline Gender-Male (\%) & 80.0 & 86.7 & 0.24 & 0.62 \\
\hline IQ $($ mean \pm SD) & $85.25 \pm 15.98$ & $84.53 \pm 23.60$ & -0.10 & 0.92 \\
\hline Diagnosis & & & 2.69 & 0.26 \\
\hline Autistic Disorder (\%) & 66.7 & 40.0 & & \\
\hline PDD-NOS (\%) & 33.3 & 53.3 & & \\
\hline Asperger's Disorder (\%) & 0 & 6.7 & & \\
\hline \multicolumn{5}{|l|}{ Severity of Disorder $($ mean \pm SD) } \\
\hline ADI-R Social Interaction & $19.20 \pm 6.73$ & $21.07 \pm 7.15$ & 0.74 & 0.47 \\
\hline ADI-R Communication & $14.20 \pm 4.30$ & $11.93 \pm 4.42$ & -1.43 & 0.17 \\
\hline ADI-R Stereotyped Behavior & $4.73 \pm 2.81$ & $3.93 \pm 2.91$ & -0.77 & 0.45 \\
\hline \multicolumn{5}{|c|}{$\begin{array}{l}\text { Notes. ADI-R }=\text { Autism Diagnostic Interview-Revised; IQ }=\text { Intelligence quotient as assessed by } \\
\text { the Chinese version of Wechsler Intelligence Scale for Children-Third Edition or the Stanford-Binet } \\
\text { Intelligence Scale-Fourth Edition; PDD-NOS = Pervasive Developmental Disorders, Not Otherwise } \\
\text { Specified. }\end{array}$} \\
\hline
\end{tabular}


set using 19 electrodes positioned across the scalp according to the International 10-20 System [53]. With electrode imped ances maintained at $\leq 10 \mathrm{k} \Omega$, the EEG signals were referenced to linked ears at a 256 sampling rate, with a high-frequency limit band pass of $30 \mathrm{~Hz}$.

Following the baseline assessments, the children in the experimental group and their parents were guided to change their lifestyle according to the $\mathrm{DMBI}$, and were followed up individually once a month for six months at the Chanwuyi Research Center for Neuropsychological Well-Being of the Chinese University of Hong Kong. Children in the control group were asked to maintain their usual daily lifestyle. After six months, the same assessments were performed on the children and their parents. Children who completed the study received a brief individual report on their pre-post cognitive functioning, which served as an incentive to encourage compliance to the study.

\section{Measures}

\section{Neuropsychological Assessments}

The d2 Test of Attention (d2) [54]. This is a test of selective attention and inhibitory control, which requires the child to cancel as many 'd's with two dashes as possible within 20 seconds for each row of stimuli, while ignoring the non-target distracters (i.e.,' $d$ 's without two dashes or 'p's). The concentration performance score was used as an overall measure of accurate response selection and inhibition, with higher scores indicating better performance. The total number of commission errors (i.e., cancellation of distractors) was counted as a measure of disinhibitory control, with lower scores indicating better self-control.

Children's Color Trails Test (CCTT) [55]. The second trial of the CCTT, which requires the child to connect numbers 1 to 15 in ascending order while alternating between two colors, was adopted as a test of mental flexibility. Shorter completion times and fewer errors (i.e., wrong connection of number or color) indicate more flexible thinking.

The Tower of California Test (ToC) [56]. The ToC was adopted as a test of planning ability, strategy formulation, and inhibition. It consists of nine items that require the participant to move discs among three vertical pegs to match a target arrangement while adhering to certain rules (i.e., no more than one disc can be moved at a time and a larger disc cannot be placed on top of a smaller disc). A low rule violation ratio (total number of rule violations/total number of items attempted) reflects better inhibitory control. Higher total achievement scores, measured by the successful completion of items with accurate and efficient movements, indicate better planning.

\section{Parental Evaluation on Behavioral Measures}

Behavior Rating Inventory of Executive Function (BRIEF) [57]. The BRIEF requires parents to rate how often their child exhibits behavior that causes difficulty in daily functioning. The 86 items tap the child's behavioral manifestation of eight ex- ecutive function domains, with frequency rated as "never," "sometimes," or "often." The Global Executive Composite was computed as an overall measure of executive functions, with higher scores indicating poorer executive functioning.

Hyperactivity Subscales of the Children's Psychiatric Rating Scale (CPRS) [58] and Conners' Rating Scales - Revised (CRS-R) [59]. These two subscales were selected as a measure of inhibitory control of behavior and emotion. The CPRS rates four self-control aspects on a scale from 0 to 6 , and the CRS-R rates 10 disinhibition-related items on a scale from 0 to 3. The total subscale scores were computed separately for comparison, with higher scores indicating poorer inhibitory control.

Lethargy Subscale of the Aberrant Behavior Checklist (ABC) [60] and Sociability Subscale of the Autism Treatment Evaluation Checklist [61]. These subscales tap the degree of appropriate forms of social behavior (e.g., initiation of an appropriate social response while inhibiting inappropriate responses), which rely largely on normal executive functioning. The $A B C$ subscale comprises 16 items rated from 0 to 3 , while the ATEC subscale comprises 20 items rated from 0 to 2 . Total subscale scores were computed separately, with higher scores indicating greater deficits in social behavior.

Speech/Language/Communication Subscale of the ATEC [61]. This subscale measures verbal communication ability in children with ASD. This subscale was selected because speech production depends partly on frontal lobe functions and such deficits are common in ASD. The 14 items are rated from 0 to 2, and higher subscale scores indicate greater verbal communication problems.

\section{Event-related EEG Assessment}

The event-related EEG signals of each child were collected while they were performing the Go/No-Go task, a computerized executive control test that measures the ability to flexibly select and execute appropriate response to changing stimuli and to inhibit unwanted responses. Details of the Go/No-Go task have been described in two previous studies $[28,44]$. The EEG epochs during the No-Go condition were extracted for analysis using MatLab 7.1 because this condition entails both the executive control processes of selecting to withhold a response and actually inhibiting a response. The epoch limit was set as $50 \mathrm{~ms}$ at the start and $900 \mathrm{~ms}$ at the end. Artifacts in the epoched data were then pruned by visual inspection and by the rejection method on the EEG Plot. The selected data were exported and then spectrally processed by fast Fourier transformation to compute the power data for the theta $(4-7.5 \mathrm{~Hz})$ frequency band using the NeuroGuide software. The theta band was selected because the ACC (one of our ROIs) is a major source generator of neural activity in the theta band [62-64] and brain oscillation at this bandwidth has repeatedly been found to be associated with attention and inhibitory control processes $[44,64]$.

The selected fast Fourier transformed data were analyzed using standardized low-resolution brain electromagnetic 
tomography analyses (sLORETA). The sLORETA method is a properly standardized inverse solution that solves the problem of computing the three-dimensional cortical distribution of the electric neuronal source activity from the scalp-EEG measurements to yield images of standardized current density with exact and zero-error localization [65]. The sLORETA solution space consists of 6,239 voxels (voxel size: $5 \times 5 \times 5 \mathrm{~mm}$ ) and is restricted to cortical gray matter and the hippocampi, as defined by the digitized Montreal Neurological Institute (MNI) 152 template [66]. Scalp electrode coordinates on the MNI brain are derived from the international $5 \%$ system [67]. A number of recent studies have validated the reliability of sLORETA and its applicability and sensitivity in experimental and clinical research [68-71]. In the present study, sLORETA was used to localize the source of scalp-EEG activity in terms of the current density in the ROls, including the IFC (BA10/47), DLPFC (BA9/46), pSMA (BA6), and ACC (BA24/32) during the No-Go condition, and the built-in paired $t$ statistics were used to compare the pre-post difference in current density in the ROls for each group of participants.

\section{Chinese Chan-based Lifestyle Intervention}

The Chinese Chan-based lifestyle intervention is also referred to as the Dejian mind-body intervention (DMBI). The children in the experimental group and their parents learned the lifestyle change, and the progress was monitored by a monthly meeting. The parents and children can refer to the books [32] and the website (www.chanwuyi.org) for details of the principles behind the DMBI and the related practicing materials (e.g., Nei Gong videos, diet recommendations). The children in the control group did not receive the DMBI and were reminded to maintain their daily habits as usual during the six-month period.

Four major aspects of the DMBI were adopted as the intervention protocol for the experimental group: 1) parenting guidance; 2) dietary recommendation; 3) practice of mindbody exercised (i.e., Nei Gong); and 4) clearance of the bodily orifices (i.e., openings). Given that children with ASD may have impaired comprehension or difficulty in self-initiating the treatment regimen, their parents played a major role in monitoring their children's daily application of the intervention methods at home.

First, the parents of the experimental group children were provided with psycho-education and guidance on parenting techniques in accordance with the Chinese Chan and Buddhism principles, with the goal of facilitating the development of a more harmonious parent-child relationship. They were guided to increase awareness of how their negative thoughts and emotions affected them and the parent-child relationship. They were encouraged to be more accepting and considerate towards their child's difficulties. Fostering a better parent-child relationship was intended to reduce tension in the family, which should have a positive effect on alleviating the child's emotional and behavioral problems.
Second, the children were encouraged to reduce their intake of hot and spicy foods (including ginger, garlic, green onion, spicy foods, eggs, meat, and fish), which according to the Chan medicine principle generate excessive internal heat and adversely affect behavior and cognitive functioning. They were advised to gradually cut down their intake according to their own lifestyles and plans. Meanwhile, to ensure a well-balanced nutritional diet, they were advised to eat according to the following seven food categories every day: fresh vegetables, fruit, grain, beans, mushrooms, nuts, and root vegetables (e.g., yam, taro). The types and amounts of food were not specified, as long as they were fresh and seasonal and the children ate until they were $80 \%$ full at each meal. According to the dietary log completed by the parents, two out of fifteen children had completely abstained from all hot and spicy foods and consumed foods from all seven recommended categories. The majority (93\%) of the children had reduced or abstained from consumption of ginger, garlic, green onion, and spicy foods, and more than half (53\%) had reduced or abstained from consumption of eggs.

Third, the children were encouraged to learn and practice some simple forms of Nei Gong, consisting of breathing exercises and slow, gentle, and calm movements such as tranquil stand, shoulder relaxation, nasal bridge massage, and Qi-smoothing movements. The functions of the exercises are two-fold: 1) to improve overall physical and psychological health by reducing stress, increasing the strength and flexibility of the four limbs, and smoothing the circulation of $Q i$ and blood; 2) to foster better self-awareness and self-control through practicing some forms of Nei Gong that serve as selfguided massage (e.g., rolling the hands slowly up and down between the chest and the abdomen; resting the hands on the abdomen) to relax and calm oneself when feeling distressed and frustrated. Given that the physical condition of the children varied, to avoid exhaustion they were instructed to stop doing the exercise until they began sweating, and thus the duration of practice was not fixed. According to their parents' reports, the children practiced on average for 10-15 minutes per day.

The fourth treatment component was designed to clear the bodily orifices by means of dietary change, regular practice of nasal bridge massage, and a daily application of a nasal cleanser. The nasal cavity and intestine (related to bowel movements) are two important bodily orifices, and unblocking them is crucial for health maintenance according to the Chan medicine model. Dietary changes, nasal cleanser, and nasal bridge massage are helpful for unblocking the nasal cavity and improving bowel function.

\section{Data Analyses}

An intention-to-treat analysis was performed to compare the pre-post scores on various neuropsychological measures of executive functions and parental ratings of problem behavior for each group of children using repeated measures ANOVA 
Chan et al., Journal of Autism 2020,

http://www.hoajonline.com/journals/pdf/2054-992X-7-1.pdf

doi: 10.7243/2054-992X-7-1

followed by post hoc paired $t$ tests. The analyses were conducted using the SPSS software. Given that specific hypotheses were tested, no adjustment to the alpha level was applied to avoid reducing the power of the tests. The effect sizes and confidence intervals were used to evaluate the extent of pre-post changes for each group. Furthermore, sLORETA analyses using voxel-by-voxel paired-sample $t$ tests for each group of children were performed to compare the pre-post changes in theta current density level in the ROls during the No-Go condition.

\section{Results}

DMBI Improved Executive Functions in ASD children Separate independent samples ttests were performed to compare the performance of the two groups of children on each neuropsychological test measure in the baseline. Results of independent samples ttests showed that the two groups of children demonstrated comparable levels of performance across the three neuropsychological tests of executive functions. The $t$ values range from -1.78 to 2.07 , and $p$ values range from 0.06 to 0.78 . Repeated measures ANOVAs were used to compare the pre-post performance between groups, with time (pre vs. post) as the within-subject factor and group (control vs. experimental) as the between-subject factor. A significant time by group interaction was found for most measures; $F$ range $=4.25$ to $8.07, p<0.05$. All tests showed a significant main effect of time; $F$ range $=5.07$ to $17.13, p<0.05$.

The results of the post hoc paired samples $t$ tests showed that children in the DMBI group demonstrated a significant improvement on all six measures of executive functions, including response selection and inhibition, mental flexibility, and planning abilities, $t$ range $=-5.07$ to $2.72, p<0.05$, with medium to large effect sizes from 0.59 to 1.35 (Table 2). In contrast, children in the control group, who did not change their lifestyle throughout the six-month period, did not show such improvements (Table 2). Although the control group demonstrated some improvement on two measures (CCTT: time and ToC: total achievement score; $\mathrm{t}=2.39$ and -2.20 , effect size $=0.64$ and 0.59 respectively, $p<0.05$ ), the extent of improvement in the experimental group was four times greater than that in the control group (CCTT: -33.24 in the experimental group vs. -7.29 in the control group; ToC: 4.38 in the experimental group vs. 1.36 in the control group) and the differences were statistically significant, $t=-2.06$ and 2.18 , respectively, $p<0.05$.

In summary, the children who had changed their lifestyle according to the Chan medicine model demonstrated significant improvements on executive function tasks compared with their control counterparts. These positive findings are consistent with those of our previous randomized controlled studies on the short-term (one month) effect of Chan-based lifestyle intervention on ASD children [25,28], and thus provide support for the effectiveness of the lifestyle intervention over a longer term (six months).

\section{More Positive Parental Ratings of Daily Executive Func- tions after DMBI}

At baseline, there was no difference between the ratings of

Table 2. Mean Performance in Executive Functioning of the Control and Experimental Groups at Pre- and Post-Six-Month Period.

\begin{tabular}{|c|c|c|c|c|c|c|c|c|c|c|}
\hline & \multicolumn{2}{|c|}{$\begin{array}{l}\text { Control Group } \\
\quad(n=15)\end{array}$} & \multirow[t]{2}{*}{$p$ value } & \multirow[t]{2}{*}{ E.S. } & \multirow[t]{2}{*}{ C.I. } & \multicolumn{2}{|c|}{$\begin{array}{l}\text { Experimental Group } \\
\qquad(n=15)\end{array}$} & \multirow[t]{2}{*}{$p$ value } & \multirow[t]{2}{*}{ E.S. } & \multirow[t]{2}{*}{ C.I. } \\
\hline & Pre & Post & & & & Pre & Post & & & \\
\hline \multicolumn{11}{|l|}{ Response Selection and Inhibition } \\
\hline d2: concentration performance & $\begin{array}{l}131.07 \\
(45.96)\end{array}$ & $\begin{array}{l}132.21 \\
(35.77)\end{array}$ & 0.929 & 0.02 & $-28.48-26.19$ & $\begin{array}{c}96.07 \\
(57.28)\end{array}$ & $\begin{array}{l}141.14 \\
(63.34)\end{array}$ & $0.000 * *$ & $1.35++$ & $-64.29--25.86$ \\
\hline d2: commission" & $\begin{array}{c}9.43 \\
(17.91)\end{array}$ & $\begin{array}{c}4.43 \\
(5.72)\end{array}$ & 0.206 & 0.36 & $-3.12-13.12$ & $\begin{array}{c}21.93 \\
(29.87)\end{array}$ & $\begin{array}{c}7.00 \\
(10.44)\end{array}$ & $0.023^{*}$ & $0.69+$ & $2.43-27.43$ \\
\hline ToC: $\mathrm{RVR}^{\#}$ & $\begin{array}{c}1.01 \\
(0.97)\end{array}$ & $\begin{array}{c}1.00 \\
(1.09)\end{array}$ & 0.935 & 0.02 & $-0.25-0.27$ & $\begin{array}{c}0.95 \\
(0.91)\end{array}$ & $\begin{array}{c}0.37 \\
(0.58)\end{array}$ & $0.018^{*}$ & $0.85++$ & $-0.08-1.44$ \\
\hline \multicolumn{11}{|l|}{ Mental Flexibility } \\
\hline CCTT: error & $\begin{array}{c}0.50 \\
(0.76)\end{array}$ & $\begin{array}{c}0.36 \\
(0.63)\end{array}$ & 0.547 & 0.16 & $-0.36-0.64$ & $\begin{array}{c}1.93 \\
(2.46)\end{array}$ & $\begin{array}{c}0.71 \\
(0.91)\end{array}$ & $0.048^{*}$ & $0.59+$ & $0.01-2.42$ \\
\hline CCTT: time (in seconds) & $\begin{array}{c}52.00 \\
(21.00)\end{array}$ & $\begin{array}{c}44.71 \\
(20.11)\end{array}$ & $0.033^{*}$ & $0.64+$ & $0.70-13.87$ & $\begin{array}{c}82.38 \\
(58.73)\end{array}$ & $\begin{array}{c}49.14 \\
(20.62)\end{array}$ & $0.017^{*}$ & $0.73+$ & $6.84-59.63$ \\
\hline \multicolumn{11}{|l|}{ Planning } \\
\hline ToC: TAS & $\begin{array}{c}9.00 \\
(4.66)\end{array}$ & $\begin{array}{l}10.36 \\
(5.43)\end{array}$ & $0.046^{*}$ & $0.59+$ & $-2.69--0.02$ & $\begin{array}{c}9.62 \\
(6.45)\end{array}$ & $\begin{array}{l}14.00 \\
(5.72)\end{array}$ & $0.005^{*}$ & $0.95++$ & $-7.17--1.60$ \\
\hline
\end{tabular}


the control and experimental group parents regarding the severity of daily behavior related to executive dysfunction, as measured by five standardized questionnaires; $t$ range $=$ -1.51 to $1.31, p>0.05$. After six months, the children who had changed their lifestyle were reported to have fewer behavioral problems related to executive functions, including abilities of self-control, socialization, and communication, whereas children in the control group did not show such improvement. Repeated measures ANOVAs showed significant or marginally significant group by time interaction effects on the Lethargy subscale of the $A B C, F=4.70, p=0.04$, the Speech/Language/ Communication subscale of the ATEC, $F=34.50, p=0.00$, and the Hyperactivity subscale of the CRS-R, $F=3.97, p=0.06$; and a significant main effect of time on the Hyperactivity subscale of the CPRS, $F=7.55, p=0.01$.

Table 3 presents the mean ratings and the post hoc paired $t$ statistics of the six behavioral indices before and after six months. Parental ratings in the experimental group showed significant or marginally significant improvements in all behavioral problems associated with executive functions, $t=2.08$ to $2.78, p=0.02$ to 0.06 , with medium effect sizes $(0.54-0.72)$. In contrast, the control group did not show such improvements after six months, and there was even a significant post-sixmonth deterioration in language communication ability as rated by the parents on the ATEC, $t=-6.83, p=0.00$. On average, the ratings of the experimental group showed improvements of around $31 \%$ across the six measures of executive behavior. On the contrary, there was a decline of about $18 \%$ in the control group. Therefore, the parents' reports of improved executive functions in the experimental group children were consistent with the enhanced executive functions measured by neuropsychological tests.

\section{Enhanced Frontal Cortex and Anterior Cingulate Cortex Activity after DMBI}

Given the significant improvement in executive functions and daily executive behavior in the experimental group, further source localization analysis by sLORETA was used to explore potential changes in their neural activity patterns while performing the executive control task (i.e., the $\mathrm{Go} / \mathrm{No}$ Go task). Theta source activities in the ROls (IFC: BA10/47; DLPFC: BA9/46; pSMA: BA6; ACC: BA24/32) were compared separately for each group before and after the six-month period using the sLORETA voxel-by-voxel paired $t$ statistics during the No-Go condition.

After six months of DMBI, the experimental group showed significantly elevated theta current density power across all ROls during the No-Go condition, $t$ maximum $=9.4, p<0.05$ (lower image in Figure 1). In contrast, the control group did not show a significant change in current density at any coordinate within the ROls after six months, $t$ maximum $=$ $1.65, p>0.05$ (upper image in Figure 1). Table 4 presents the corresponding number of voxels with significantly increased current density and their distribution across different ROIs. In the experimental group, a total of 509 voxels within the ROIs showed above-threshold increments in current density power during the No-Go condition. Inspection of the distribution of significant voxels in each hemisphere revealed that the ACC

Table 3. Mean Parental Rating on Children from the Control and Experimental Groups Before and After Six Months.

\begin{tabular}{|c|c|c|c|c|c|c|c|c|c|c|}
\hline \multirow{3}{*}{$\begin{array}{l}\text { Cognitive Domain / Measures } \\
\text { Overall Executive Functions }\end{array}$} & \multicolumn{2}{|c|}{$\begin{array}{l}\text { Control Group } \\
\quad(n=15)\end{array}$} & \multirow[t]{2}{*}{$p$ value } & \multirow[t]{3}{*}{ E.S. } & \multirow[t]{3}{*}{ C.I. } & \multicolumn{2}{|c|}{$\begin{array}{l}\text { Experimental Group } \\
\qquad(n=15)\end{array}$} & \multirow[t]{2}{*}{$p$ value } & \multirow[t]{2}{*}{ E.S. } & \multirow[t]{2}{*}{ C.I. } \\
\hline & Pre & Post & & & & Pre & Post & & & \\
\hline & & & & & & & & & & \\
\hline BRIEF-GEC & $\begin{array}{l}150.29 \\
(18.78)\end{array}$ & $\begin{array}{l}148.93 \\
(18.67)\end{array}$ & 0.74 & 0.09 & $-7.43-10.14$ & $\begin{array}{l}150.07 \\
(34.03)\end{array}$ & $\begin{array}{l}140.47 \\
(29.80)\end{array}$ & 0.06 & $0.54+$ & $-0.30-19.50$ \\
\hline \multicolumn{11}{|l|}{ Self-Control Ability } \\
\hline CPRS-H & $\begin{array}{c}8.43 \\
(4.78)\end{array}$ & $\begin{array}{c}7.14 \\
(5.25)\end{array}$ & 0.28 & 0.30 & $-1.19-3.76$ & $\begin{array}{l}8.67 \\
(6.18)\end{array}$ & $\begin{array}{c}5.27 \\
(3.26)\end{array}$ & $0.02 *$ & $0.70+$ & $0.71-6.09$ \\
\hline CRS-R-H & $\begin{array}{c}9.33 \\
(4.30)\end{array}$ & $\begin{array}{l}10.07 \\
(5.70)\end{array}$ & 0.59 & 0.14 & $-3.57-2.10$ & $\begin{array}{c}9.67 \\
(7.15)\end{array}$ & $\begin{array}{c}7.00 \\
(4.96)\end{array}$ & $0.03^{*}$ & $0.64+$ & $0.35-4.98$ \\
\hline \multicolumn{11}{|l|}{ Sociability } \\
\hline ABC-L & $\begin{array}{l}14.33 \\
(7.26)\end{array}$ & $\begin{array}{l}13.73 \\
(6.15)\end{array}$ & 0.68 & 0.11 & $-2.44-3.64$ & $\begin{array}{l}13.00 \\
(8.28)\end{array}$ & $\begin{array}{c}6.40 \\
(6.12)\end{array}$ & $0.02 *$ & $0.72+$ & $1.50-11.70$ \\
\hline ATEC-II & $\begin{array}{l}12.47 \\
(6.77)\end{array}$ & $\begin{array}{l}12.87 \\
(7.04)\end{array}$ & 0.83 & 0.06 & $-4.24-3.44$ & $\begin{array}{l}12.40 \\
(5.45)\end{array}$ & $\begin{array}{c}9.73 \\
(5.31)\end{array}$ & $0.03^{*}$ & $0.62+$ & $0.26-5.07$ \\
\hline \multicolumn{11}{|l|}{ Communication Ability } \\
\hline ATEC-I & $\begin{array}{c}4.80 \\
(3.21)\end{array}$ & $\begin{array}{l}10.33 \\
(2.55)\end{array}$ & $0.00^{* * *}$ & $1.77++$ & $-7.27--3.80$ & $\begin{array}{c}7.13 \\
(6.10)\end{array}$ & $\begin{array}{c}4.27 \\
(2.87)\end{array}$ & $0.03^{*}$ & $0.63+$ & $0.34-5.39$ \\
\hline
\end{tabular}

Note. $\quad \mathrm{ABC}-\mathrm{L}=$ Lethargy Subscale of the Aberrant Behavior Checklist; ATEC-I = Speech $/$ Lanuage/Communication Subscale of the Autism Treatment Evaluation Checklist; ATEC-II = Sociability Subscale of the Autism Treatment Evaluation Checklist; BRIEF-GEC $=$ Global Executive Composite of the Behavior Rating Inventory of Executive Function; CPRS-H = Hyperactivity Subscale of the Children's Psychiatric Rating Scale; CRS-R-H = Hyperactivity Subscale of the Conners' Rating Scale-Reivsed. E.S. = Effect size; C.I. = Upper and lower limits of the 95\% confidence interval. Standard deviations are in parenthesis. Lower value indicates less severe problems; ${ }^{*} p<0.05,{ }^{* *} p<0.01 ;+$ medium effect size. 


\section{Control Group}
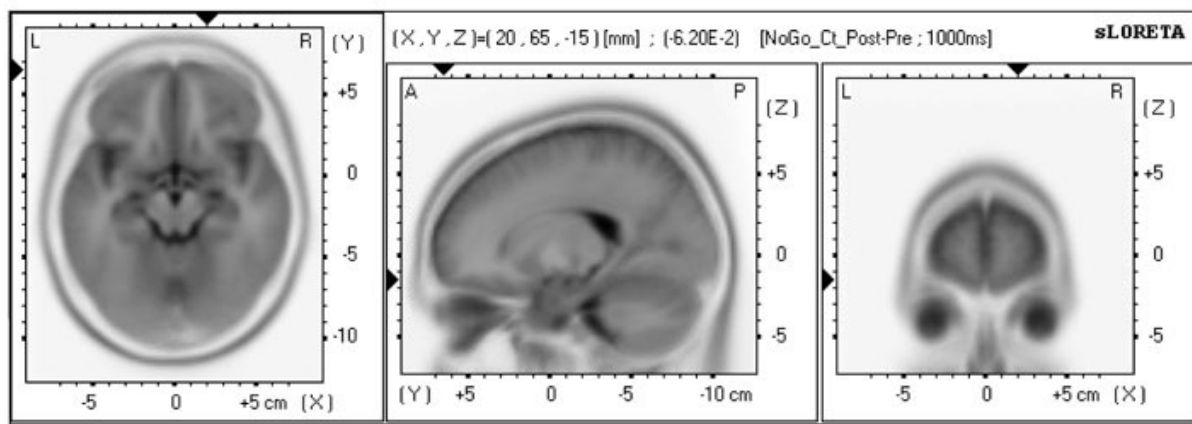

\section{Experimental Group}

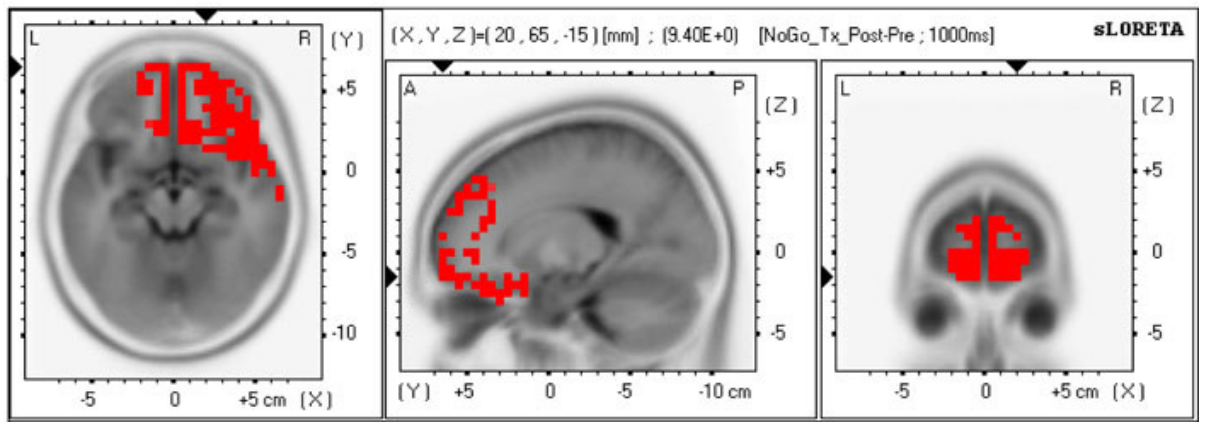

Figure 1. Neuro-electrophysiological activity changes at the end of the six-month intervention.

Graphical representation of sLORETA paired t-statistics comparing the pre- and post-six-month theta source activity of the control and experimental groups during the No-Go condition. The experimental group demonstrated significantly elevated current density (shown in red) in the anterior cingulate cortex, inferior frontal cortex, dorsolateral prefrontal cortex, and presupplementary motor area during the No-Go condition after six months ( $\max . t=9.4, p<0.05$ ), whereas the control group did not show any significant change.

Table 4. Total Amount and Distribution of Cortical Voxels Showing Significantly Increased Theta Current Density Localized at the Regions of Interests of the Control and Experimental Groups at No-Go condition after Six Months.

\begin{tabular}{|c|c|c|c|c|c|}
\hline \multirow[t]{2}{*}{ Group } & \multirow[t]{2}{*}{ Anatomical Regions (Abbreviation) } & \multirow{2}{*}{$\begin{array}{c}\text { Brodmann Areas } \\
\text { (BAs) }\end{array}$} & \multicolumn{2}{|c|}{ No. of Sig. Voxels } & \multirow[t]{2}{*}{ Max. $t$ value } \\
\hline & & & Left & Right & \\
\hline \multirow[t]{7}{*}{ Control } & Anterior Cingulate Cortex (ACC) & 24 & - & - & 0.00 \\
\hline & & 32 & - & - & 0.00 \\
\hline & Inferior Frontal Cortex (IFC) & 10 & - & - & 0.72 \\
\hline & & 47 & - & - & 0.73 \\
\hline & Dorsolateral Prefrontal Cortex (DLPFC) & 9 & - & - & 0.80 \\
\hline & & 46 & - & - & 0.62 \\
\hline & Pre-supplementary Motor Area (pSMA) & 6 & - & - & 0.41 \\
\hline \multirow[t]{7}{*}{ Experimental } & Anterior Cingulate Cortex (ACC) & 24 & 8 & 10 & $4.79 *$ \\
\hline & & 32 & 31 & 43 & $7.79 *$ \\
\hline & Inferior Frontal Cortex (IFC) & 10 & 57 & 134 & $9.29^{*}$ \\
\hline & & 47 & - & 108 & $8.03^{*}$ \\
\hline & Dorsolateral Prefrontal Cortex (DLPFC) & 9 & 28 & 57 & $6.78^{*}$ \\
\hline & & 46 & - & 21 & $6.84^{*}$ \\
\hline & Pre-supplementary Motor Area (pSMA) & 6 & 1 & 11 & $3.34 *$ \\
\hline
\end{tabular}

Note. No. of Sig. Voxels $=$ Number of voxels at the left and the right hemisphere of the cortex with significantly increased current density above the $t$ threshold value $\left({ }^{*} p<0.05\right)$. Max. $t$ value $=$ The highest $t$ value within a specific region of interest indicating the greatest significant increase in current density power. 
was more bilaterally involved, whereas the IFC, DLPFC, and pSMA were more right-lateralized. As revealed by the maximum $t$ value, the IFC (BA10/47) and ACC (BA32) showed the greatest pre-post difference. However, in the control group, there was no significant change in the current density power for any voxel within the ROls.

The present findings are consistent with our previous results, thus demonstrating that the significantly increased ACC current density was associated with the treatment effect of DMBI. Furthermore, the elevated current density in the IFC, DLPFC, and SPMR, which coincided with the enhanced ACC current density, is consistent with the distributed functional network that has been proposed to mediate response selection and inhibition [46-48]. Such treatment-specific alteration in neural oscillation within the anterior and medial brain regions provides a possible explanation for the enhanced test performance and improved daily behavior related to a wide range of executive functions in the treatment group.

\section{Discussion}

The study revealed improvements in executive function and daily behavior in the experimental group children after changing their lifestyle according to the Chinese Chan medicine concept for six months. Such positive treatment outcomes were consistent with our previous randomized controlled trials reporting the specific effects of a one-month Chan medicinebased diet modification [28] and the practice of Nei Gong [25] on executive functions in ASD children. Comparison of the extent of improvement in the short-term and long-term studies revealed a relatively more robust enhancement over a longer period. First, the extent of improvement in the present study in terms of the scope and magnitude of pre-post changes in executive functions was relatively greater than that reported in previous studies. In specific, the present results showed a consistent improvement in response selection, inhibitory control, mental flexibility, and planning abilities across tests with an improvement of approximately $40-68 \%$ in test scores, which is higher than the $17-42 \%$ improvement on the same test measures in the previous one-month intervention [28]. Furthermore, the extent of improvement in parental ratings of executive functions was consistent across five standardized questionnaires in the present study, which was more robust than the specific improvement in one or two measures of inhibitory control and social communication reported in previous studies $[25,28]$. This further increase in treatment effects could be due to daily application of the Chan-based lifestyle intervention over a longer period that may facilitate progressive improvement in ASD children compared with its short-term effect. This postulation was hinted at in our previous single case studies $[27,29]$ and other unreported clinical observations on the progressively improving trend in ASD individuals after receiving Chan-based intervention for at least three months and up to four years.

The effect of the Chan-based lifestyle change was found not only at the behavioral level, but also at the neural processing level. Cumulative empirical evidence has suggested that suppressed frontal region and ACC activity in individuals with ASD is associated with the impairment of executive functions manifested in daily life [43-44,49-50]. The present study replicated the previous findings of DMBI-induced increases in event-related theta oscillation localized to the ACC in ASD. Suppressed ACC functional activity has repeatedly been found to be associated with various deficits in emotional processing, inhibitory control, and conflict-monitoring in individuals with ASD [43-44]. Functional abnormality in the ACC has also been found in many neurological and psychiatric disorders, e.g., attention-deficit/hyperactivity disorder [72], depression [73], and schizophrenia [74]. Adding to our previous shortterm studies, the present findings provide further support for the long-term effects of the Chan-based intervention on current density power in the ACC, which suggests the possibility of applying the Chan-based lifestyle intervention as a neuropsychological rehabilitation approach for patients with ACC dysfunctions.

Another important finding is that the treatment enhanced the current density in the IFC, DLPFC, and SPMR, which in combination with the ACC comprises the large neural network underlying the stimulus-response monitoring process. Particularly, the IFC in the right hemisphere has been suggested as a key region for response inhibition in normal individuals [75] and repeatedly reported to show abnormal activation and reduced functional connectivity with other inhibition-related brain regions in ASD population [49,76]. In our present study, children who have applied the Chan-based lifestyle change demonstrated the greatest degree of postintervention elevation in the current density at the right IFC. The greatest degree of changes in the IFC is reflected by the highest $t$ value which indicates the most significant pre-post difference and the three to four times more number of voxels having significant difference at the IFC, as compared to that of the ACC, DLPFC and SPMR.

The potential benefits of the Chan-based lifestyle intervention are consistent with the treatment effects of some conventional behavioral-based interventions and alternative mind-body interventions for enhancing executive functions and related behavioral and emotional problems in ASD [36,8-11]. It should be noted that about 10 minutes of daily $\mathrm{Nei}$ Gong practice and a once a month follow-up for monitoring the children's progress and providing guidance to their parents was sufficient to reveal some cognitive and behavioral improvement in ASD children. Given the simplicity and costeffectiveness of this proposed Chan-based intervention, individuals with ASD who were of limited intelligence were able to follow the treatment regime with minimal assistance from their caregivers. It can also be applied in families with lower socioeconomic status as it does not require very intensive training or any special equipment. Therefore, the Chan-based lifestyle intervention can be considered as a cost-effective 
intervention for improving executive functioning in children across the autistic spectrum.

Despite the encouraging findings on the intervention effect, there are some limitations of present study. Although some potential confounding factors, e.g., age, gender, level of intelligence, baseline level of cognitive functions, were matched between groups, it is worth exploring some other factors that might have impact on the intervention effect, e.g., parent's subjective feedback about the intervention, children's involvement of other forms intervention within the study period, the psychological condition of children and their parents. Besides, it is worthwhile to conduct a randomized controlled trial to further verify the intervention effect found in present study. In addition, since the parents were not blinded to the experimental condition, their rating on children's behaviors might be biased. To increase objectivity, it is also worthwhile to add qualitative analysis on children's behavior by a blinded examiner or to invite children's school teacher who are blinded to the treatment to rate on children's daily behaviors in future studies.

The present study provides evidence of the positive longterm effects of the Chan-based lifestyle intervention on executive functions and their underlying neural mechanisms in children with ASD. Given that executive function deficits are common in patients with various brain disorders (e.g., attention-deficit/hyperactivity disorder, traumatic brain injury, dementia), it may also worth extending our investigation of this intervention to other clinical populations. Also, given the increasing research interest in applying mind-body interventions (e.g., yoga) to improve health in Western countries, the applicability and effectiveness of this Chinese Chan-based intervention in the Caucasian population could also be investigated in future studies.

\section{Conclusion}

This study provides support for the long-term therapeutic effects of a Chinese Chan-based lifestyle intervention (i.e., the Dejian mind-body intervention) on a wide range of executive functions measured by neuropsychological tests and daily behavioral checklists, which are in line with the increased current density power in the ACC and frontal lobe. Such encouraging findings provide added support for the effectiveness of the Chinese Chan-based lifestyle intervention for ASD and shed some light on its potential clinical applicability for improving executive functions and altering the neural processing patterns of people suffering from frontal lobe dysfunctions.

\section{Competing interests}

The authors declare that they have no competing interests.

\section{Acknowledgements}

The authors would especially like to thank Venerable Master Dejian of the Songshan Monastery. They are also thankful to the parents and the principals and teachers of the San Wui Commercial Society School and the Chi Lin Secondary School who participated in this study and/or assisted in recruiting participants. Appreciation is also extended to Debbie Yan, Lan He, Man-ying Mo, Queenie Wong, Rex Wong, and Karoline Chiu for their efforts in data collection and data management.

Authors' contributions

\begin{tabular}{|l|c|c|}
\hline Authors' contributions & ASC & SLS \\
\hline Research concept and design & $\checkmark$ & -- \\
\hline Collection and/or assembly of data & -- & $\checkmark$ \\
\hline Data analysis and interpretation & $\checkmark$ & $\checkmark$ \\
\hline Writing the article & -- & $\checkmark$ \\
\hline Critical revision of the article & $\checkmark$ & -- \\
\hline Final approval of article & $\checkmark$ & -- \\
\hline Statistical analysis & -- & $\checkmark$ \\
\hline
\end{tabular}

\section{Publication history}

Editor: David Reiss, Imperial College London, UK. Received: 10-Dec-2019 Final Revised: 17-Jan-2020 Accepted: 10-Feb-2020 Published: 16-Feb-2020

\section{References}

1. Kenworthy L, Yerys BE, Anthony LG and Wallace GL: Understanding executive control in autism spectrum disorders in the lab and in the real world. Neuropsychol Rev 2008, 18:320-338, https://doi.org/10.1007/ s11065-008-9077-7

2. Sanders J, Johnson KA, Garavan H, Gill M and Gallagher L: A review of neuropsychological neuroimaging research in autistic spectrum disorders: Attention, inhibition and cognitive flexibility. Res Autism Spectr Disord 2008, 2:1-16, https://doi.org/10.1016/j.rasd.2007.03.005

3. Goin-Kochel RP, Myers BJ and Mackintosh VH: Parental reports on the use of treatments and therapies for children with autism spectrum disorders. Res Autism Spectr Disord 2007, 1:195-209, https://doi. org/10.1016/j.rasd.2006.08.006

4. National Research Council: Educating Children with Autism 2001.

5. Ospina MB, Seida JK, Clark B, Karkhaneh M, Hartling L, Tjosvold L, Vandermeer B and Smith V: Behavioral and developmental interventions for autism spectrum disorder: A clinical systematic review. PLOS ONE 2008, 3:e3755, https://doi.org/10.1371/journal.pone.0003755

6. Vismara LA and Rogers SJ: Behavioral treatments in autism spectrum disorder: what do we know? Annu Rev Clin Psychol 2010, 6:447-468, https://doi.org/10.1146/annurev.clinpsy.121208.131151

7. Matson JL and Smith KRM: Current status of intensive behavioral interventions for young children with autism and PDD-NOS. Res Autism Spectr Disord 2008, 2:60-74, https://doi.org/10.1016/j.rasd.2007.03.003

8. Silva LMT, Cignolini A, Warren R, Budden S and Skowron-Gooch A: Improvement in sensory impairment and social interaction in young children with autism following treatment with an original qigong massage methodology. Am J Chin Med 2007, 35:393-406, https://doi. org/10.1142/S0192415X07004916

9. Cheuk DKL, Wong V and Chen WX: Acupuncture for autism spectrum disorders (ASD). Cochrane Database Syst Rev 2011, 9, https://doi. org/10.1002/14651858.CD007849.pub2.

10. Gold C, Wigram T and Elefant C: Music therapy for autistic spectrum disorder. Cochrane Database Syst Rev 2006, 2, https://doi. org/10.1002/14651858.CD004381.pub2

11. Mulloy A, Lang R, O’Reilly M, Sigafoos J, Lancioni G, and Rispoli M: Gluten-free and casein-free diets in the treatment of autism spectrum disorders: a systematic review. Res Autism Spectr Disord 2010, 4:328339, https://doi.org/10.1016/j.rasd.2009.10.008

12. Hyman SL and Levy SE: Dietary, complementary and alternative therapies. In Reichow B, Doehring P, Cicchetti DV and Volkmar FR (Eds.), Evidence-Based Practices and Treatments for Children with Autism. 2011, 275-293.

13. Martin A, Saunders DH, Shenkin SD and Sproule J: Lifestyle intervention 
for improving school achievement in overweight or obese children and adolescents. Cochrane Database Syst Rev 2014, 3, https://doi. org/10.1002/14651858.CD009728.

14. Merrill DA and Small GW: Prevention in psychiatry: Effects of healthy lifestyle on cognition. Psychiatr Clin N Am 2011, 34:249-261, https://doi. org/10.1016/j.psc.2010.11.009

15. Small GW, Silverman DHS, Siddarth P, Ercoli LM, Miller KJ, Lavretsky H, Wright BC, Bookheimer SY, Barrio JR and Phelps ME: Effects of a 14-day healthy longevity lifestyle program on cognition and brain function. Am J Geriatr Psychiatry 2006, 14:538-545, https://doi.org/10.1097/01. JGP.0000219279.72210.ca

16. Walsh R: Lifestyle and mental health. Am Psychol 2011, 66:579-592, https://doi.org/10.1037/a0021769

17. Chan AS, Ho YC, Cheung MC, Albert MS, Chiu HF and Lam LC: Association between mind-body and cardiovascular exercises and memory in older adults. J Am Geriatr Soc 2005, 53:1754-1760, https://doi.org/10.1111/ j.1532-5415.2005.53513.x

18. Ho YC and Chan AS: Comparing the effects of mahjong playing and reading on cognitive reserve of the elderly. J Psychol in Chin Soc 2005, 6:5-26.

19. Small BJ, Dixon RA, McArdle JJ and Grimm KJ: Do changes in lifestyle engagement moderate cognitive decline in normal aging? Evidence from the Victoria Longitudinal Study. Neuropsychology 2012, 26:144155.

20. Valenzuela $M$ and Sachdev, P: Can cognitive exercise prevent the onset of dementia? Systematic review of randomized clinical trials with longitudinal follow-up. Am J Geriatr Psychiatry 2009, 17:179-187, https://doi.org/10.1097/JGP.0b013e3181953b57

21. Voss MW, Prakash RS, Erickson KI, Basak C, Chaddock L, Kim JS, Alves H, Heo S, Szabo AN, White SM, Wójcicki TR, Mailey EL, Gothe N, Olson EA, McAuley E and Kramer AF: Plasticity of brain networks in a randomized intervention trial of exercise training in older adults. Front Aging Neurosci 2010, 2, 32. https://doi.org/10.3389/fnagi.2010.00032

22. Chaddock L, Pontifex MB, Hillman CH and Kramer AF: A review of the relation of aerobic fitness and physical activity to brain structure and function in children. J Int Neuropsychol Soc 2011, 17:975-985, https:// doi.org/10.1017/S1355617711000567

23. Chan $A$, Cheung $M$ and Sze $S$ : Effect of mind/body training on children with behavioral and learning problems: a randomized controlled study. In DeLuca B (Ed.), Mind-body and Relaxation Research Focus 2008, 165-193.

24. Corripio R, Gónzalez-Clemente JM, Jacobo PS, Silvia N, Lluis G, Joan V and Assumpta C: Plasma brain-derived neurotrophic factor in prepubertal obese children: Results from a 2-year lifestyle intervention programme. Clin Endocrinol 2012, 77:715-720, https://doi.org/10.1111/j.13652265.2012.04431.x

25. Chan AS, Sze SL, Siu NY, Lau EM and Cheung MC: A Chinese mind-body exercise improves self-control of children with autism: A randomized controlled trial. PLoS One 2013, 8(7), e68184, doi.org/10.1371/journal. pone.0068184

26. Chan AS, Han YMY, Cheung MC: Chinese Chan-based prospective neuropsychological intervention for autistic children. In Patel VB, Preedy VR and Martin CR (Eds.), The Comprehensive Guide to Autism 2014, 2333-2355.

27. Chan AS, Sze SL, Cheung MC, Han YMY, Leung WWM and Shi D: Dejian mind-body intervention improves the cognitive functions of a child with autism. Evid Based Complement Alternat Med 2011, 2011, doi:10.1155/2011/549254.

28. Chan AS, Sze SL, Han YMY and Cheung MC: A Chan dietary intervention enhances executive functions and anterior cingulate activity in autism spectrum disorders: a randomized controlled trial. Evid Based Complement Alternat Med 2012, 1-11, https://doi. org/10.1155/2012/262136

29. Chan AS, Sze SL and Shi D: Traditional Chinese mind-body exercises improve self control ability of an adolescent with Asperger's disorder. $J$ Psychol Chin Soc 2008, 9:225-239.
30. Chan AS, Han YMY, Sze SL and Lau EM: Neuroenhancement of memory for children with autism by a mind-body exercise. Front Psychol 2015, 6:1893, https://doi.org/10.3389/fpsyg.2015.01893

31. Chan AS: The Shaolin Chanwuyi: A Chinese Chan Buddhism 2010.

32. Chan AS: Contemporary Application of Shaolin Medicine: Dejian MindBody Intervention ( th $^{\text {th }}$ ed.) 2013 (in Chinese).

33. Chan AS, Cheung MC, Tsui WJ, Sze SL and Shi D: Dejian mind-body intervention on depressive mood of community-dwelling adults: A randomized controlled trial. Evid Based Complement Alternat Med 2011, 2011, 1-8, https://doi.org/10.1093/ecam/nep043

34. Chan AS, Cheung MC, Sze SL, Leung WWM and Shi D: Shaolin Dan Tian breathing fosters relaxed and attentive mind: A randomized controlled neuroelectrophysiological study. Evidence-Based Complementary and Alternative Medicine 2011, 2011:1-11, https://doi. org/10.1155/2011/180704

35. Chan AS, Cheung WK, Yeung MK and Lee TL: Sustained effects of memory and lifestyle interventions on memory functioning of older adults: An 18-month follow-up study. Front Aging Neurosci 2018, 10:240, https://doi.org/10.3389/fnagi.2018.00240

36. Chan AS, Cheung WK, Yeung MK, Woo J, Kwok T, Shum DHK, Yu R and Cheung M: A Chinese Chan-based mind-body intervention improves memory of older adults. Front Aging Neurosci 2017, 9:190, https://doi. org/10.3389/fnagi.2017.00190

37. Chan AS, Sze SL, Woo J and Yu RH: A Chinese Chan-based lifestyle intervention improves memory of older adults. Front Aging Neurosci 2014, 6:50, https://doi.org/10.3389/fnagi.2014.00050

38. Yu R, Woo J, Chan AS and Sze SL: A Chinese Chan-based mind-body intervention improves psychological well-being and physical health of community-dwelling elderly: A pilot study. Clin Interv Aging 2014, 9:727, https://doi.org/10.2147/CIA.S59985

39. Chan AS, Sze SL, Cheung MC, Lam JMK and Shi D: Dejian mindbody intervention improves the functioning of a patient with chronic epilepsy: A case report. Cases J 2009, 2:9080, https://doi. org/10.1186/1757-1626-2-9080

40. Chan AS, Wong QY, Sze SL, Kwong PPK, Han YMY and Cheung MC: A Chinese Chan-based mind-body intervention improves sleep on patients with depression: a randomized controlled trial. ScientificWorldJournal 2012, 2012, https://dx.doi.org/ 10.1100/2012/235206

41. Chan AS, Wong QY, Sze SL, Kwong PPK, Han YMY and Cheung MC: A Chinese Chan-based mind-body intervention for patients with depression. J Affect Disord 2012, 142:283-289, https://doi.org/10.1016/j. jad.2012.05.018

42. Chan AS, Han YMY, Sze SL, Wong QY and Cheung MC: A randomized controlled neurophysiological study of a Chinese Chan-based mindbody intervention in patients with major depressive disorder. EvidenceBased Complementary and Alternative Medicine 2013, 2013, https:// dx.doi.org/ 10.1155/2013/812096

43. Agam Y, Joseph RM, Barton JJS and Manoach DS: Reduced cognitive control of response inhibition by the anterior cingulate cortex in autism spectrum disorders. Neuroimage 2010, 52:336-347.

44. Chan AS, Han YMY, Leung WWM, Leung C, Wong VCN and Cheung MC: Abnormalities in the anterior cingulate cortex associated with attentional and inhibitory control deficits: A neurophysiological study on children with autism spectrum disorders. Res Autism Spectr Disord 2011, 5:254-266, https://doi.org/10.1016/j.rasd.2010.04.007

45. Langen M, Leemans A, Johnston P, Ecker C, Daly E, Murphy CM, dell'Acqua F, Durston S, AIMS Consortium and Murphy DGM: Frontostriatal circuitry and inhibitory control in autism: findings from diffusion tensor imaging tractography. Cortex 2012, 48:183-193, https://doi. org/10.1016/j.cortex.2011.05.018

46. Chambers $C D$, Garavan $H$ and Bellgrove MA: Insights into the neural basis of response inhibition from cognitive and clinical neuroscience. Neurosci Biobehav Rev 2009, 33:631-646, https://doi.org/10.1016/j. neubiorev.2008.08.016

47. Kiesel A, Steinhauser M, Wendt M, Falkenstein M, Jost K, Philipp AM and Koch I: Control and interference in task switching - A review. Psychol 
Chan et al., Journal of Autism 2020,

http://www.hoajonline.com/journals/pdf/2054-992X-7-1.pdf

Bull 2010, 136:849-874

48. Simmonds DJ, Pekar JJ and Mostofsky SH: Meta-analysis of Go/No-go tasks demonstrating that $\mathrm{fMRI}$ activation associated with response inhibition is task-dependent. Neuropsychologia 2008, 46:224-232, https://doi.org/10.1016/j.neuropsychologia.2007.07.015

49. Kana RK, Keller TA, Minshew NJ and Just MA: Inhibitory control in high-functioning autism: Decreased activation and underconnectivity in inhibition networks. Biol Psychiatry 2007, 62:198-206, https://doi. org/10.1016/j.biopsych.2006.08.004

50. Philip RCM, Dauvermann MR, Whalley HC, Baynham K, Lawrie SM and Stanfield AC: A systematic review and meta-analysis of the fMRI investigation of autism spectrum disorders. Neurosci Biobehav Rev 2012, 36:901-942, https://doi.org/10.1016/j.neubiorev.2011.10.008

51. American Psychiatric Association: Diagnostic and Statistical Manual of Mental Disorders. (5 $5^{\text {th }}$ ed.) 2013.

52. Lord C, Rutter M and Couteur AL: Autism diagnostic interview-revised: a revised version of a diagnostic interview for caregivers of individuals with possible pervasive developmental disorders. J Autism Dev Disord 1994, 24:659-685, https://doi.org/10.1007/BF02172145

53. Klem GH, Lüders HO, Jasper HH and Elger C: The ten-twenty electrode system of the International Federation. The International Federation of Clinical Neurophysiology. Electroencephalogr Clin Neurophysiol Suppl 1999, 52:3-6.

54. Brickenkamp R and Zillmer E: The d2 Test of Attention 1998.

55. Williams J, Rickert V, Hogan J, Zolten AJ, Satz P, D'Elia LF, Asarnow RF, Zaucha K and Light R: Children's color trails. Arch Clin Neuropsychol 1995, 10:211-223, https://doi.org/10.1016/0887-6177(94)00041-N

56. Delis DC, Kaplan E and Kramer JH: Delis-Kaplan Executive Function Scale: Standardization Edition Manual 1997.

57. Gioia GA, Isquith K, Guy SC and Kenworthy L: Behavior Rating Inventory of Executive Function (BRIEF) 2000.

58. Fish B: Children's psychiatric rating scale. Psychopharmacol Bull 1985, 21:753-764.

59. Conners CK: Conners' Rating Scales-Revised: Technical Manual 1997.

60. Aman MG, Singh NN, Stewart AW and Field CJ: The aberrant behavior checklist: A behavior rating scale for the assessment of treatment effects. Am J Ment Defic 1985, 89:485-491.

61. Autism Treatment Evaluation Checklist: Reliabilities and score distributions. Autism Research Institute 2019. Available at: [https://www. autism.org/autism-treatment-evaluation-checklist/]

62. Asada H, Fukuda Y, Tsunoda S, Yamaguchi M and Tonoike M: Frontal midline theta rhythms reflect alternative activation of prefrontal cortex and anterior cingulate cortex in humans. Neurosci Lett 1999, 274:29-32, https://doi.org/10.1016/S0304-3940(99)00679-5

63. Ishii R, Shinosaki K, Ukai S, Inouye T, Ishihara T, Yoshimine T, Hirabuki N, Asada $\mathrm{H}$, Kihara T, Robinson SE and Takeda M: Medial prefrontal cortex generates frontal midline theta rhythm. Neuroreport 1999, 10:675-679.

64. Hermens DF, Soei EXC, Clarke SD, Kohn MR, Gordon E and Williams LM: Resting EEG theta activity predicts cognitive performance in attentiondeficit hyperactivity disorder. Pediatr Neurol 2005, 32:248-256, https:// doi.org/10.1016/j.pediatrneurol.2004.11.009

65. Pascual-Marqui RD: Standardized Low-Resolution Brain Electromagnetic Tomography (sLORETA): Technical details. Methods Find Exp Clin Pharmacol 2002, 24:5-12.

66. Fuchs M, Kastner J, Wagner M, Hawes S and Ebersole JS: A standardized boundary element method volume conductor model. Clin Neurophysiol 2002, 113:702-712, https://doi.org/10.1016/S1388-2457(02)00030-5

67. Jurcak V, Tsuzuki D and Dan I: 10/20, 10/10, and 10/5 systems revisited: Their validity as relative head-surface-based positioning systems. Neuroimage 2007, 34:1600-1611, https://doi.org/10.1016/j. neuroimage.2006.09.024

68. Michels L, Bucher K, Luchinger R, Klaver P, Martin E, Jeanmonod D and Brandeis D: Simultaneous EEG-fMRI during a working memory task: Modulations in low and high frequency bands. PLOS ONE 2010, 5: e10298, https://doi.org/10.1371/journal.pone.0010298
69. Dumpelmann M, Ball T and Schulze-Bonhage A: sLORETA allows reliable distributed source reconstruction based on subdural strip and grid recordings. Hum Brain Mapp 2012, 33:1172-1188, https://doi. org/10.1002/hbm.21276

70. De Ridder D, Vanneste S, Kovacs S, Sunaert S and Dom G: Transient alcohol craving suppression by rTMS of dorsal anterior cingulate: An fMRI and LORETA EEG study. Neurosci Lett 2011, 496:5-10, https://doi. org/10.1016/j.neulet.2011.03.074

71. Dierks T, Jelic V, Pascual-Marqui RD, Wahlund L, Julin P, Linden, D. E., Maurer K., Winblad, B and Nordberg A: Spatial pattern of cerebral glucose metabolism (PET) correlates with localization of intracerebral EEG-generators in Alzheimer's disease. Clin Neurophysiol 2000, 111:1817-1824, https://doi.org/10.1016/S1388-2457(00)00427-2

72. Hart H, Radua J, Mataix-Cols D and Rubia K: Meta-analysis of fMRI studies of timing in attention-deficit hyperactivity disorder. Neurosci Biobehav Rev 2012, 36:2248-2256, https://doi.org/10.1016/j. neubiorev.2012.08.003

73. Hamani C, Mayberg H, Stone S, Laxton A, Haber S and Lozano AM: The subcallosal cingulate cortex in the context of major depression. Biol Psychiatry 2011, 69:301-308, https://doi.org/10.1016/j. biopsych.2010.09.034

74. Ikuta T, Szeszko PR, Gruner P, DeRosse P, Gallego J and Malhotra AK Abnormal anterior cingulate cortex activity predicts functional disability in schizophrenia. Schizophr Res 2012, 137:267-268, https://doi. org/10.1016/j.schres.2011.12.021

75. Aron AR, Robbins TW and Poldrack RA: Inhibition and the right inferior frontal cortex. Trends Cogn Sci 2004, 8:170-177, https://doi. org/10.1016/j.tics.2004.02.010

76. Lee PS, Yerys BE, Rosa AD, Foss-Feig J, Barnes KA, James JD, VanMeter J, Vaidya CJ, Gaillard, WD and Kenworthy LE: Functional connectivity of the inferior frontal cortex changes with age in children with autism spectrum disorders: A fcMRI study of response inhibition. Cereb Cortex 2009, 19:1787-1794, https://doi.org/10.1093/cercor/bhn209

\section{Citation:}

Chan AS and Sze SL. Changing Lifestyle Improves Executive Functions and Associated Neurophysiological Activity in Children with Autism. J Autism. 2020; 7:1. http://dx.doi.org/10.7243/2054-992X-7-1 